\title{
Analysis on the Runoff and Sediment Yielding of "7.26" Rainstorm in 2017 in the Dali River Basin
}

\author{
WenYong Gao, ShuangYan Jin and ShaoMeng Guo \\ (Yellow River Institute of Hydrology and Water Resources, Zhengzhou 450004, China)
}

\begin{abstract}
Hydrological regimes of the "7.26" rainstorm and flood in 2017 in the Dali River basin are illustrated, the runoff and sediment of the flood is calculated. The relationship between peak discharge, runoff and sediment of history floods and the corresponding mean rainfall and combined rainfall factor are established respectively. It is found that the point of "7.26" flood locates at the upper left or in the middle of the history points group. The results show that after the implementation of water and soil conservation and ecological restoration policy for several decades, the underlying surface of the Dali River basin has changed to some degree, but encountered with the high intensity rainfall such as "7.26", it will still generate the flood of high sediment concentration.
\end{abstract}

\section{Introduction}

The high intensity rainfall occurred in the most of the north Shanxi and Shaanxi region of the middle Yellow River from July 25 to July 26 in 2017, and the rainstorm region located in the Dali River, the tributary of the Wuding River. The flood occurred in the trunk stream and tributary of Dali River in succession due to the rainfall. The peak discharge of Suide hydrological station in the trunk was $3290 \mathrm{~m}^{3} / \mathrm{s}$, which occurred at 5:05 on July 26 , the largest flood since the establishment of the station in 1959. Compared with history flood, what was the quantity of runoff and sediment yielding by this rainstorm based on current underlying? The researchers carried out the investigation in the rainstorm region and analyzed the water and sand amount during this flood.

\section{Brief Introduction of the Dali River basin}

The Dali River is the largest tributary of Wuding River in the middle Yellow River. It locates southern part of Yulin, Shaanxi Province, and at the east longitude $109^{\circ} 14^{\prime} \sim 110^{\circ} 13^{\prime}$ and north latitude $37^{\circ} 30^{\prime} \sim 37^{\circ} 56^{\prime}$. It originates from the East of Baiyu mountain in Jingbian county and the South boundary of the Maowusu Desert, flows through Jingbian, Hengshan, Ansai, Zichang, Zizhou county from West to East, and finally inflows into the Wuding River at northeast of Suide county. The total length of the main stream is $170 \mathrm{~km}$, the area of the river basin is $3906 \mathrm{~km}^{2}$, the height difference is $503.3 \mathrm{~m}$, and the ratio of the river bed is $3.16 \%$.

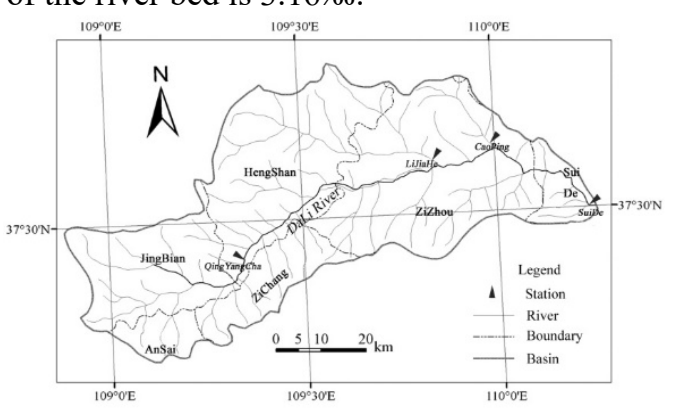

Fig.1 The location of the Dali River basin

The controlling station entering the Wuding River is Suide hydrological station, with catchment area of $3893 \mathrm{~km}^{2}$, which accounts for $99.7 \%$ of the whole basin area. The major tributaries are Xiaoli River, Chabagou and so on.

The geomorphic of the Dali River basin is the Loess Hilly and Gully region (Li, 2010; Ran, 2011; Wang, 2008; $\mathrm{Li}, 2015)$. The average annual soil erosion modulus is above $12000 \mathrm{t} / \mathrm{km}^{2}$, and the soil erosion is serious. It is one of the main source areas of coarse sediment in the Yellow River basin.

\footnotetext{
*Corresponding author: E-mail: 1178922805@qq.com
} 


\section{Rainfall, Runoff and Sediment of " 7.26 " Flood}

\subsection{Rainfall}

The rainstorm occurred in the most of the north Shanxi and Shaanxi region of the middle Yellow River from July 25 to July 26 in 2017, and the heavy rain occurred in the Dali River. The rainstorm process is from 17:00 on July 25 to 7:00 on July 26, and the duration is 14 hours. There are 7 rainfall stations of the rainfall over than $200 \mathrm{~mm}$ (shown in Table 1 and Figure 2). The main rainfall lasts 8 hours from 22:00 on July 25 to 6:00 on the next day, the rainfall occupies $89 \%$ of the total amount, and the peak rainfall occurred at July 26 2:00. The heavy rainstorm center is Zhaojiabian of Suide County, and the rainfall is $252.3 \mathrm{~mm}$. The mean rainfall of the river basin calculated by the method of isogram is $129.8 \mathrm{~mm}$. The enveloped area of $50 \mathrm{~mm}$ rainfall contour is about $3775 \mathrm{~km}^{2}$ and occupies $97 \%$ of the total basin area, which of the $100 \mathrm{~mm}$ contour is about $2753 \mathrm{~km}^{2}$ and occupies $70.7 \%$ of the total basin area (shown in Tab.2).

Tab.1 Rainfall over than 200mm at the stations from July 25 8:00 to July 26 8:00 in Dali River basin

\begin{tabular}{|c|c|c|c|c|c|c|c|}
\hline No. & River & Station & $\begin{array}{c}\text { Rainfall } \\
/ \mathrm{mm}\end{array}$ & No. & River & Station & $\begin{array}{c}\text { Rainfall } \\
/ \mathrm{mm}\end{array}$ \\
\hline 1 & Dalihe & Zizhou & 218.7 & 5 & Chabagou & Caoping & 212.2 \\
\hline 2 & Xiaolihe & Lijiawa & 218.4 & 6 & Chabagou & $\begin{array}{c}\text { Zhujiayangwa } \\
\text { n }\end{array}$ & 201.2 \\
\hline 3 & Xiaolihe & Lijiahe & 214.8 & 7 & Chabagou & Jijiajian & 200.6 \\
\hline 4 & Chabagou & Xinyaotai & 214.2 & & & & \\
\hline
\end{tabular}

Tab.2 The enveloped area of different rainfall from July 25 8:00 to July 26 8:00 in Dali River basin

\begin{tabular}{|c|c|c|c|c|c|c|c|c|c|c|}
\hline \multirow{2}{*}{ Region } & \multicolumn{8}{|c|}{ The enveloped area of different rainfall $/ \mathrm{km}^{2}$} & \multirow{2}{*}{$\begin{array}{l}\text { Area } \\
/ \mathrm{km}^{2}\end{array}$} & \multirow{2}{*}{$\begin{array}{c}\text { Mean } \\
\text { rainfall } \\
/ \mathrm{mm}\end{array}$} \\
\hline & $\begin{array}{c}20 \\
\sim\end{array}$ & $\begin{array}{c}25 \\
\sim\end{array}$ & $\begin{array}{c}50 \\
\sim\end{array}$ & $\begin{array}{c}75 \\
\sim\end{array}$ & $\begin{array}{c}100 \\
\sim\end{array}$ & $\begin{array}{c}150 \\
\sim\end{array}$ & $\begin{array}{c}200 \\
\sim\end{array}$ & $\begin{array}{c}250 \\
\sim\end{array}$ & & \\
\hline Above Caoping & 0 & 0 & 0 & 0 & 5.6 & 158.1 & 23.3 & 0 & 187 & 177.8 \\
\hline Above Lijiahe & 0 & 35.0 & 94.9 & 289.4 & 141.6 & 113.1 & 133.1 & 0 & 807 & 121.4 \\
\hline Above Qingyangcha & 0 & 83.2 & 319.9 & 226.5 & 624.0 & 6.3 & 0 & 0 & 1260 & 97.2 \\
\hline Above Suide & 0 & 118.2 & 414.8 & 606.5 & 1549 & 715.2 & 489.2 & 0 & 3893 & 129.8 \\
\hline
\end{tabular}

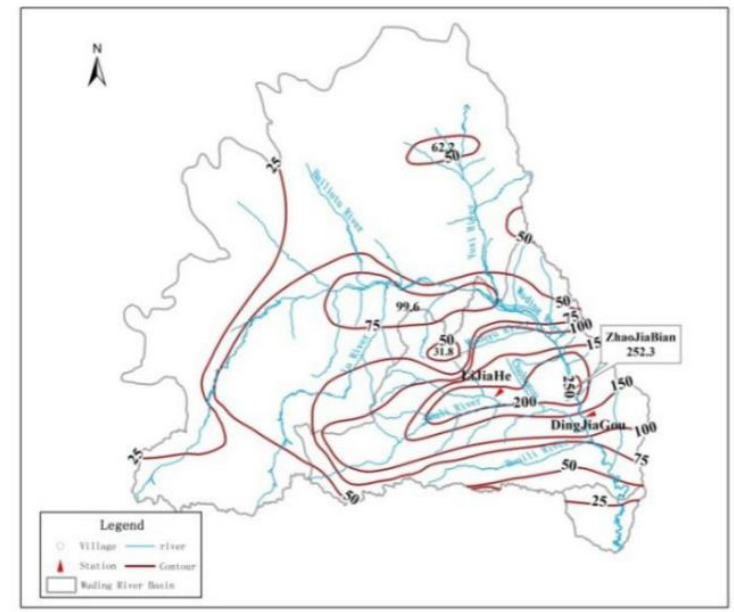

Fig.2 The isogram of rainfall in "7.26" rainstorm in Wudinghe

\subsection{Runoff and Sediment}

Due to the rainfall, the flood occurred in the trunk stream and tributary of the Dali River basin in succession. The peak discharge of the Qingyangcha hydrological station in the upper Dali River is $1800 \mathrm{~m}^{3} / \mathrm{s}$, which occurred at 4:00 on July 26 , and the maximum sediment concentration at $8: 00$ is $620 \mathrm{~kg} / \mathrm{m}^{3}$. The peak 
discharge of Lijiahe hydrological station in Xiaolihe basin is $997 \mathrm{~m}^{3} / \mathrm{s}$, the largest flood since 1994 and ranks the third in the annual maximum series, and the maximum sediment concentration at $5: 30$ is $260 \mathrm{~kg} / \mathrm{m}^{3}$. The peak flow of Caoping hydrological station in Chabagou is $299 \mathrm{~m}^{3} / \mathrm{s}$, occurred at 7:00 on July 26 , and the maximum sediment concentration at $8: 00$ is $272 \mathrm{~kg} / \mathrm{m}^{3}$. The peak discharge of Suide hydrological station is $3290 \mathrm{~m}^{3} / \mathrm{s}$, occurred at 5:05 on July 26 , and is the largest flood since the establishment of the station in 1959 (shown in Figure 3).

(1) The runoff and sediment of Suide hydrological station is relatively high. The flood in Suide station rose

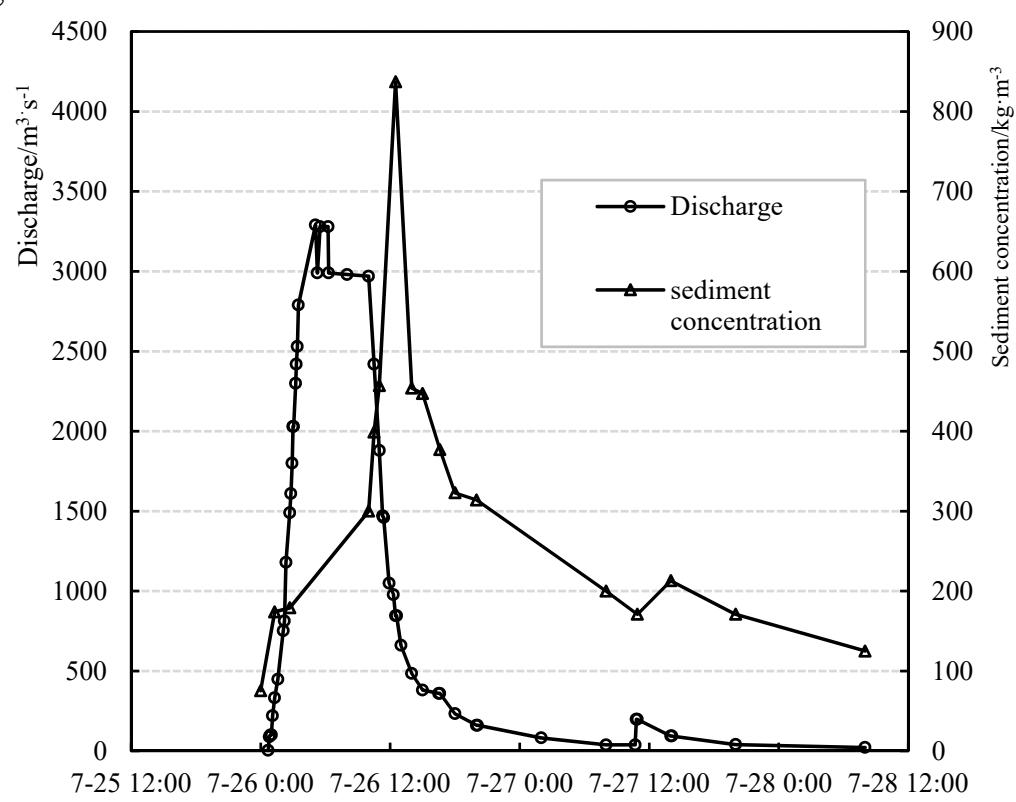

Fig.3 Graph of the discharge and sediment concentration of " $7 \cdot 26$ " flood at Suide station

Tab.3 The runoff and sediment at the major stations of " $7 \cdot 26$ " flood in Dali River basin

\begin{tabular}{|c|c|c|c|c|}
\hline River & Station & $\begin{array}{c}\text { Runoff } \\
/ 10^{4} \mathrm{~m}^{3}\end{array}$ & $\begin{array}{c}\text { Sediment } \\
/ 10^{4} \mathrm{t}\end{array}$ & $\begin{array}{c}\text { Duration } \\
\text { (d h:min } \sim \mathrm{d} \text { h:min })\end{array}$ \\
\hline Dalihe & Qingyangcha & 2229 & 1291 & 25 20:00 27 00:00 \\
\hline Xiaolihe & Lijiahe & 2263 & 361 & $2523: 00 \sim 2704: 00$ \\
\hline Chabagou & Caoping & 659 & 88 & $2521: 42 \sim 2617: 30$ \\
\hline Dalihe & Suide & 11335 & 3373 & $2600: 42 \sim 2808: 00$ \\
\hline
\end{tabular}

(2) The high water level of peak flow summit of Suide hydrology station lasts 5.5 hours. The junction of Dali River and Wuding River shows an angle of nearly $180^{\circ}$, seen from Google Earth (shown in Fig.4).

The peak discharge of Suide station in Dali River appeared at 5:05 on July 26, and of Dingjiagou station in Wuding River appeared at 4:48 on July 26 . The difference of the two peak time is 17 minutes. The Suide station is at $0: 00$ on July 26 , at the same time the discharge is $3.46 \mathrm{~m}^{3} / \mathrm{s}$ and the water level is $811.83 \mathrm{~m}$. At $5: 05$, the peak discharge is $3290 \mathrm{~m}^{3} / \mathrm{s}$ and the highest water level is $823.1 \mathrm{~m}$. The range of the water level rises up to $11.27 \mathrm{~m}$. The runoff is $1.1335 \times 10^{8} \mathrm{~m}^{3}$ (shown in Table 3), ranks the first in the history, which is 1.6 times of the runoff amount of the "8.05" flood in 1977.

The sediment transportation of this flood in Suide station is $3373 \times 10^{4} \mathrm{t}$, and ranks the fourth of the history. The former three is $5450 \times 10^{4} \mathrm{t}$ of " 8.05 " flood in 1977 , $3850 \times 10^{4} \mathrm{t}$ of " 8.19 " flood in 2001 and $3780 \times 10^{4} \mathrm{t}$ of " 8.15 " flood in 1966 respectively. 


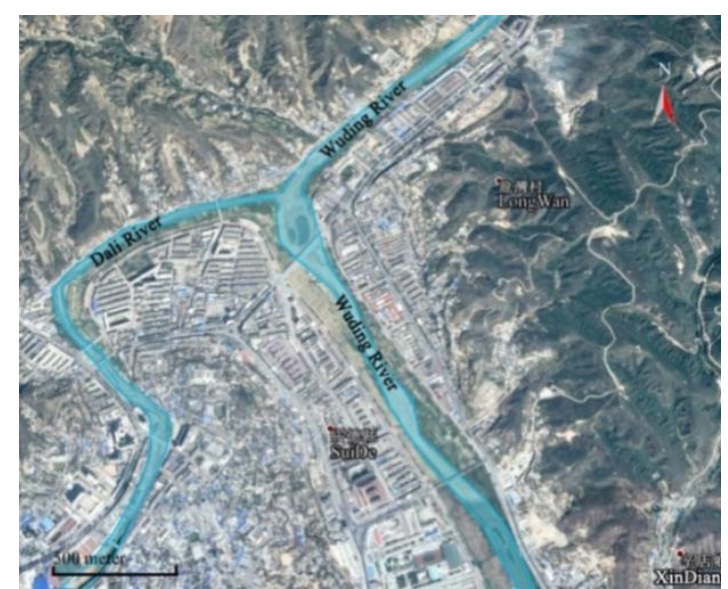

Fig.4 The confluence sketch map of Dali River and Wuding River

\section{Analysis of rainfall-water-sand relation}

Three major variables affecting flood and sediment yielding are selected when establishing the relationship of rainfall, runoff and sediment: the average rainfall corresponding to the flood $(\bar{P})$, the maximum rainfall intensity (I) of concentration period of the different percentage rainfall $(40 \% \sim 100 \%$, interval $10 \%)$, and the ratio of rainstorm covered area to the whole basin area $\left(\mathrm{F}_{\mathrm{i}}\right.$ $\left./ \mathrm{F}_{0}\right)$.

According to the result of the eleventh Five-Year National Science and Technology support program $(\mathrm{Xu}$, 2009), the optimal relationship between the independent variable, i.e. peak discharge, runoff and sediment, and the combined rainfall factor is the following:

$Q_{\mathrm{m}}=625.7 *\left(\bar{P}^{*} \mathrm{I}_{40}\right)^{0.080 *}\left(1+F_{50} / F_{\text {sum }}\right)^{0.73}$

$W_{\mathrm{w}}=202.6 *\left(\bar{P}^{*} \mathrm{I}_{40}\right)^{0.217 *}\left(1+F_{50} / F_{\text {sum }}\right)^{1.88}$

$W_{\mathrm{s}}=375 *\left(\bar{P}^{*} \mathrm{I}_{40}\right)^{0.160 *\left(1+F_{50} / F_{\text {sum }}\right)^{1.08}}$

Where: $\bar{P}$ flood $I_{40}$ the maximum rainfall intensity of concentration

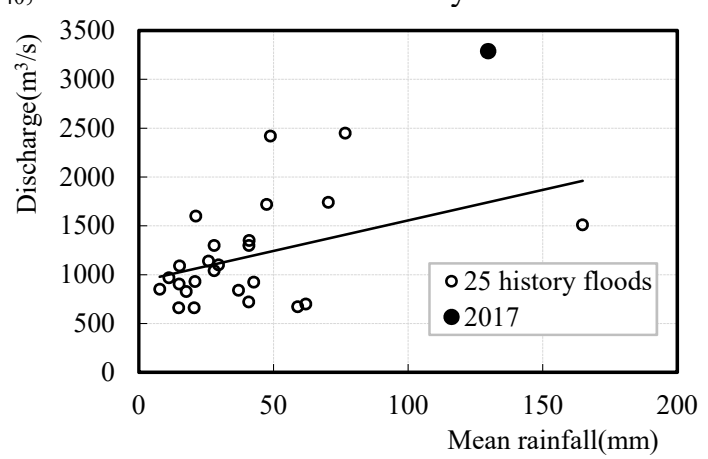

Fig.6 Relation between peak flow and $\bar{P}$

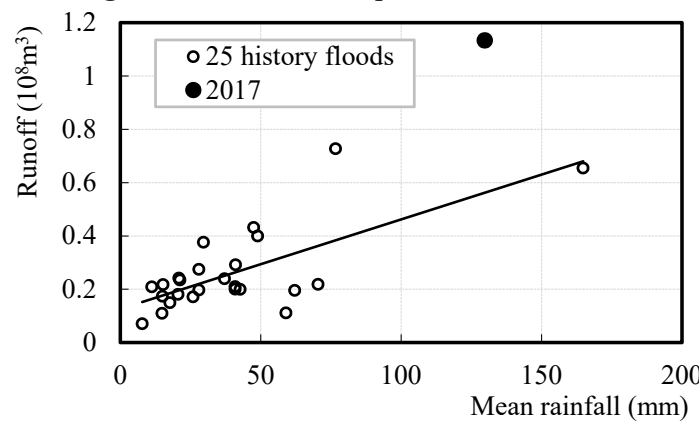

Fig.8 Relation between runoff and $\bar{P}$

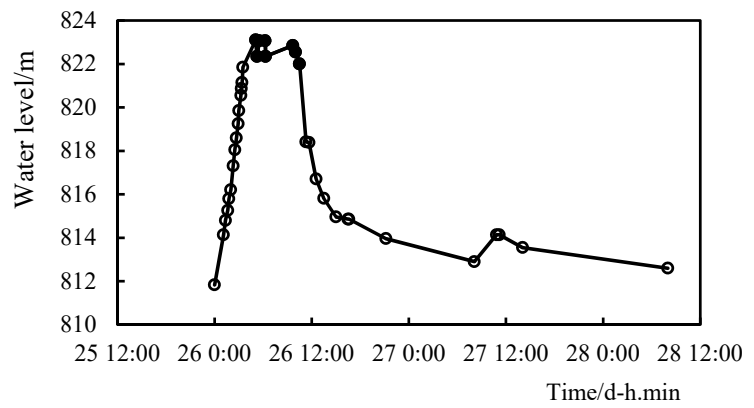

Fig.5 Graph of " $7 \cdot 26$ "flood water level at the Suide station

period of the $40 \%$ rainfall; $F_{50}$, the enveloped area of $50 \mathrm{~mm}$ rainfall; $F_{\text {sum, }}$ the area of Dali River basin.

The former 25 historical floods of the Suide hydrological station according to the peak discharge from large to small are selected, to establish the relationship between peak discharge, runoff and sediment and the corresponding mean rainfall and combined rainfall factor respectively (shown in Figure 6 11).

The peak discharge is $3290 \mathrm{~m}^{3} / \mathrm{s}$ and locates at the upper left of the points group. The runoff is $1.1335 \times 10^{8} \mathrm{~m}^{3}$ and also locates at the upper left of the points group. The sediment volume is $0.3373 \times 10^{8} \mathrm{t}$, which is slightly below the trend line and still in the middle of the points group. It shows that the underlying surface of Dali River basin has been obviously improved through the harness of water and soil conservation for $50 \sim 60$ years, but encountered the extreme heavy rainfall such as "7.26", it will still produce large peak discharge and runoff, relatively large amount of sediment.

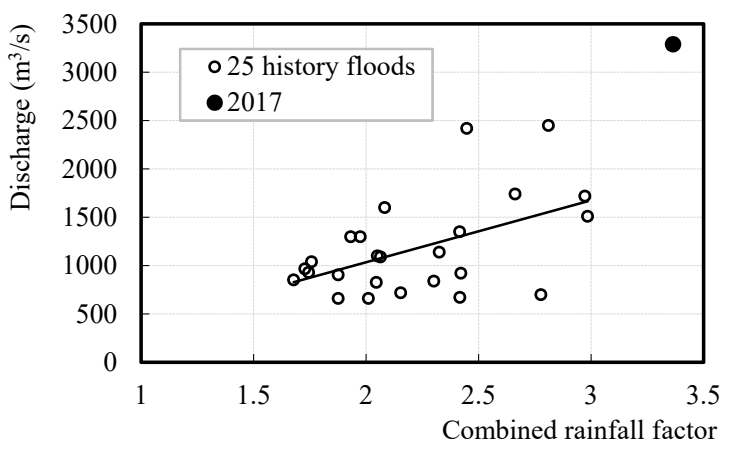

Fig.7 Relation between peak flow \& combined rainfall factor

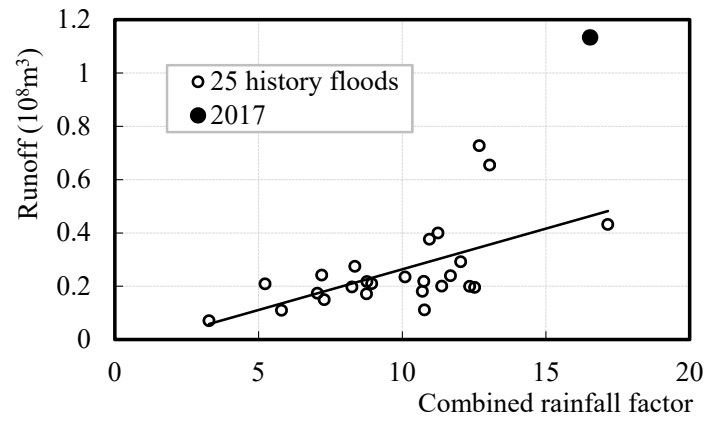

Fig.9 Relation between runoff \& combined rainfall factor 


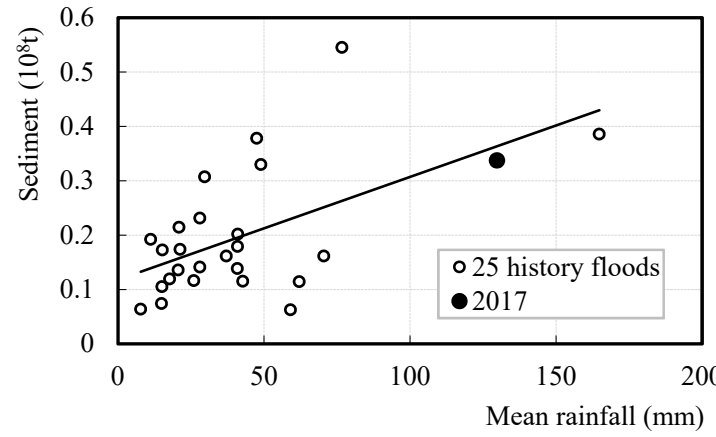

Fig.10 Relation between sediment and $\bar{P}$

\section{Initial analysis of sediment source}

(1) Vegetation Coverage. Due to the policies of returning farmland to forest and prohibiting grazing are

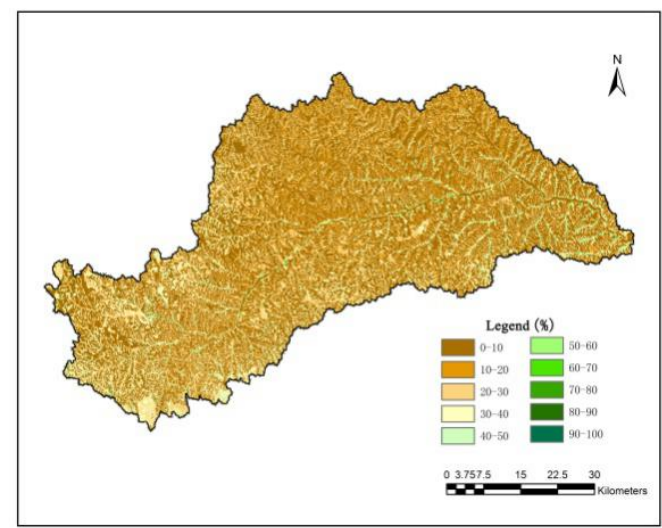

Fig.12 The vegetation coverage in August 1998 (left) and August 2012 (right) in Dali River basin

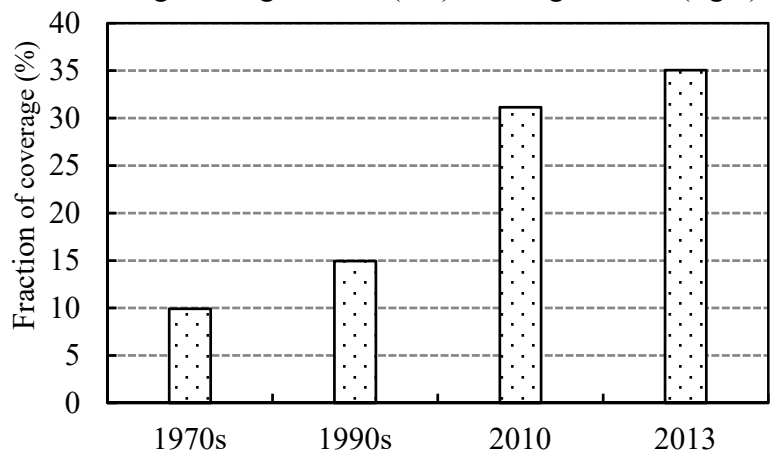

Fig.13 The fraction of vegetation coverage in different periods in Dali River basin

The rainfall during one hour in most rainfall stations of rainstorm center is $30 \sim 40 \mathrm{~mm}$, in partly stations is 50 $60 \mathrm{~mm}$, while in Lixiaohe station of Moshigou gully is up to $79 \mathrm{~mm}$. The high rainfall intensity greatly exceed antierosion of the slope farmland, rill erosion of farmland surface is obvious, and gully has developed even in some places, but rill erosion of the natural restoration farmland is relatively rare. The rill or gully erosion formed by the rainstorm basically occurred on the cultivated slope land and the economic woodland of bare surface.

(2) Terrace. There are not many new terrace fields in the Dali River basin. The scale of the cultivated sloping farmland is large, and the terraces built by machine are small. According to the results of general survey of national water conservancy, the terrace area accounts for $10 \% \sim 15 \%$ of water and soil erosion area in Zizhou county of " 7.26 " rainstorm center, and the proportion is $15 \% \sim 20 \%$ both in Mizhi and Suide county (shown in Figure 14).

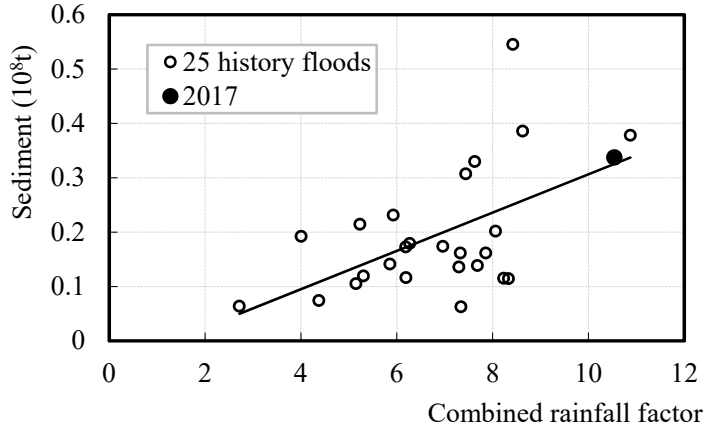

Fig.11 Relation between sediment \& combined rainfall factor implemented in Dali River basin from 1998, the vegetation coverage has been significantly improved, which increased from $9.9 \%$ in 1970 s, $14.9 \%$ in 1990 s to $35.1 \%$ in 2013 (Liu, 2016) (shown in Figure 12 13).

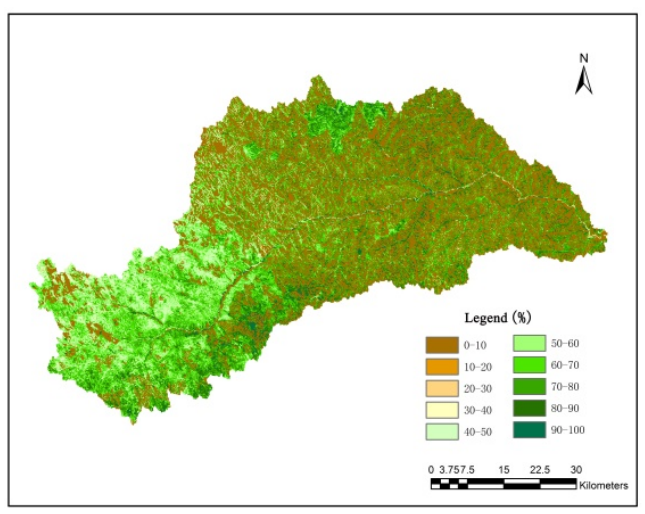

Water erosion occurred in partly old terraces in the ridge, when encountered " 7.26 " rainstorm. From deep brown traces of the damage surface, it is deduced that the most damage are not due to the "7.26" rainstorm, but the wind erosion and water erosion in the past decades. 


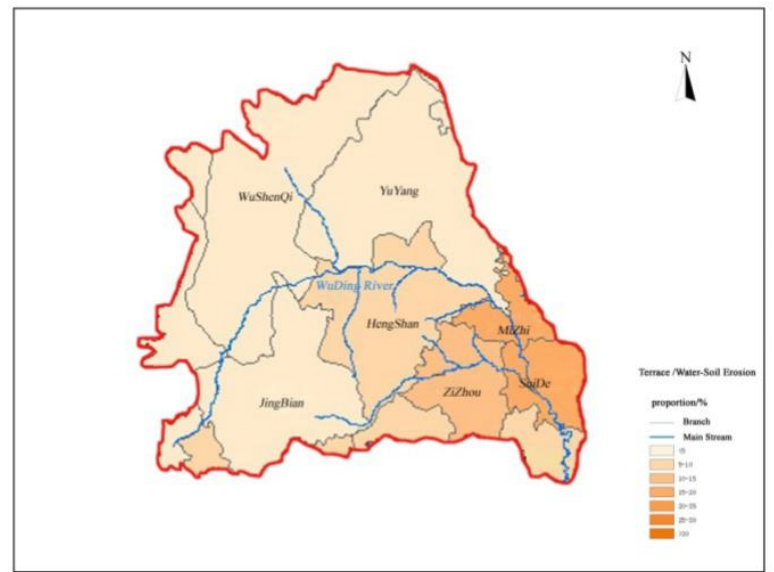

Fig.14 The terrace density in the Wuding River basin in 2011

(3) Check dam. More than 20 check dams are investigated during the field survey. The check dam without damage drained no sediment basically. The destroyed check dam has the distinct ditch near the spillway or drainage facility. The overall impression is that blocked sediment by check dam is greater than the drainage sediment due to the destroyed check dam.

(4) Gravity erosion. The slope runoff yielded when rainfall intensity is greater than the infiltration capacity in loess hilly gully region. The runoff must flow through the gutter. Due to the vegetation improved, the sediment carried by water flow is often lower than the sediment carrying capacity. Furthermore, potential energy transformed into kinetic energy, and flow velocity increase, resulting erosion and collapse in the marginal Loess Mao-slope, and large amount of sediment were carried by flow and transported downstream.

The water flows from the slope to small ditch, ditch, and then to the tributary. When the flow converges together, the velocity increases gradually, the sediment carrying capacity increases, and the ultimate limit sediment concentration also increases gradually (Qian, 1987).

(5) Others. Except the above statement, the sources of sediment still include the following aspects. The serious scouring of both sides of the river channel and the beach, the original sediment deposited in the river channel, and the extreme flushing gully-slope roads built by farmers and so on.

\section{Conclusions and Suggestions}

(1) Heavy rainfall, wide enveloped area, and more runoff and sediment. The rainfall of heavy rainstorm center of Zhaojiabian is $252.3 \mathrm{~mm}$. The mean rainfall of " 7.26 " rainstorm is $129.8 \mathrm{~mm}$, next to the year of 1977, and ranks the second of history. The enveloped area of rainfall contour of $50 \mathrm{~mm}$ and $100 \mathrm{~mm}$ account for $97 \%$ and $70.7 \%$ of the total basin area respectively. The runoff and sediment ranks the first and fourth respectively. It shows that the underlying surface of Dali River basin has been obviously improved through the harness of water and soil conservation for 50 60 years, but it will still produce large water and sand when encountered extreme heavy rainfall.

(2) The study of runoff yielding and confluence and sediment yielding and transport still need to be strengthened. Through decades of implementation of water and soil conservation and ecological restoration policy, the underlying surface of Dali River basin changed to some extent, and the hydrological situation changed greatly. The frequency of large flood decreased. However, in the long run, there is no essential change in the climate characteristics in this area. Heavy rainfall of short duration on the local or large scale still may be occurred, which will lead to large flood in the main stream and tributaries. Therefore, researchers must study the various techniques of hydrology, soil and water conservation and sediment, select small watershed, and make further strengthen the survey of underlying surface change and the influence on runoff, erosion, sediment yielding and so on. Then, adapt the analysis of the reason of water and sand change under the condition of the change of the underlying surface.

\section{Acknowledgment}

Foundation: National Key Technology R\&D Program, No. 2016YFC0402409.

\section{Author}

Gao Wenyong (1962-), specialized in hydrology and water resources.

\section{References}

1. Li Lijuan, Jiang Dejuan, Yang Junwei, et al. Study on hydrological response to land use and land cover change in Dali River basin of Shaanxi province [J]. Geographical Research, 2010,29(7):1233-1243.

2. Ran Dachuan, Zhang Zhiping, Luo Quanhua, et al. More comprehensive analysis on benefits of flood and sediment reduction of soil and water conservation measures during 1970-2002 in Dali River basin [J]. Research of Soil and Water Conservation, 2011, 18(1):17-22.

3. Wang Min, Li Zhanbin, Cui Lingzhou, et al. Study on spatial variation of geomorphy fractal character in Dali River watershed $[\mathrm{J}]$. Bulletin of Soil and Water Conservation, 2008, 28(5):104-107.

4. Li Binbin, Li Zhanbin, Li Peng. Spatial and temporal variation characteristics of vegetation cover fractal dimension in Dali River watershed based on GIS and RS [J]. Transactions of the Chinese Society of Agricultural Engineering, 2015, 31(12):173-178.

5. Xu Jianhua, Li Xiaoyu, Chen Jianjun, et al. Conservation projects impacts on flood and sediment in Hekouzhen to Longmen region $[\mathrm{M}]$. Zhengzhou: Yellow River Water Conservancy Press, 2009: 116-119.

6. Liu Xiaoyan. The causes of sharp decrease of water and sand in recent years in the Yellow River [M]. Beijing: Science Press, 2016: 96-114.

7. Qian Ning, Zhang Ren, Zhou Zhide. River bed evolution [M]. Beijing: Science Press, 1987:49-50 